\title{
Clinicopathologic and Survival Characteristics of patients with squamous cell carcinoma and adenocarcinoma of uterine cervix in Yazd, Iran
}

\author{
Fariba Binesh ${ }^{1}$, Sanaz Azadi ${ }^{1}$, Ali Akhavan², Tahmine hashemi zade ${ }^{1}$, Pegah Kamal ${ }^{1}$ \\ 1 Department of Pathology, Shahid Sadoughi University of Medical Sciences, Yazd, Iran \\ 2 Department of Radiotherapy, Isfahan University of Medical Sciences, Isfahan, Iran \\ *Corresponding Author: Dr. Fariba Binesh, Department of Pathology, Shahid Sadoughi University of Medical Sciences, Yazd, Iran. \\ Email: binesh44@yahoo.com; Tel: +983518113698
}

Received: March 25, 2020; Accepted: June 06, 2020

\section{Abstract}

Introduction: Though the incidence of cervical squamous cell cancer (SCC) has reduced during recent years, the amount of cervical adenocarcinoma (AC) has propagated. There is a controversy over whether prognosis is better in SCC or AC. Similar studies have not been conducted in Iran.

\begin{abstract}
Material and methods: This is a descriptive-analytic study that is based on historical cohort method. In this retrospective work, all cases of cancer patients were studied from 2004 to 2015 and the medical records of all women recognized with cervical SCC and AC treated in Shahid Sadoughi teaching hospital and Shahid Ramesanzadeh Radiotherapy Center were recovered. In these patients, the epidemiologic characteristics, survival and the factors affecting the survival were investigated. Statistical analysis included frequency table and Chi-Square test. Patient survival was assessed using Kaplan- Meier assessments, and multivariate analysis was done by the Cox regression mode.

Results: This study was done on 158 patients identified with cervical carcinoma. Their mean age at the time of diagnosis was $53.3987 \pm 1.02150$ years. According to histopathologic types, 132 of the patients were classified as SCC with mean age of $52.4840 \pm 1.10612$ years; while 26 patients were identified as AC with mean age of $58.0385 \pm 2.49830$ years. The overall survival was $96.338 \pm 4.434$ months (95\% confidence interval) and it was $100.459 \pm 4.342$ and $54.475 \pm 5.334$ months for SCC and AC respectively. In the early and advanced stages, overall survival of patients with SCC was different $(p=0.001)$. It was true about the patients with $A C(p=0.002)$.

Conclusion: The results of the current study showed the prognosis is worse in patients with cervical AC than cervical SCC.
\end{abstract}

Keywords: Squamous cell carcinoma, Adenocarcinoma, Uterine cervix, Survival.

\section{INTRODUCTION}

Cervical cancer is a common cancer and a worldwide health problem $(1,2)$. The cause of cervical cancer is not fully understood, although the HPV infection may be effective in creating it. Most patients have signs of abnormal vaginal bleeding and pelvic pain, but some patients have no symptoms. Cervical cancer progresses slowly and usually remains longterm without a clinical symptom. In many cases, the disease is detected during screening tests or accidentally, in cases of hysterectomy due to another reason. In advanced and invasive stages of the disease, the development of abnormal vascular pattern and other structural changes in the affected cervix causes spotting, abnormal hemorrhage or dysparunia [2]. A Pap smear test is used to diagnose and the diagnosis is confirmed by biopsy. If cervical cancer is detected early, the patient's death can be prevented by treatment. Today, due to the widespread use of the Pap smear method and possible alteration in socioeconomic index has led to reduction in cervical SCC incidence and mortality rates globally. Despite the decline in SCC death rates, this lesion is still the most common malignancy of the female reproductive system in most parts of the world. SCC occurs at any age from the age of 20 to old age, but the most commonly occurring age of the lesion is 40 to 45 years. Cervical $\mathrm{AC}$ is the second most common cervical cancer, accounting for between $15 \%$ and $20 \%$ of cervical cancers. The most common age is middle-age and $20 \%$ are over the age of 65 , but its 
absolute and relative incidences are increasing, especially in women aged 20-40 [3]. There is a controversy whether prognosis is better in SCC or AC [4, 5, 6]. This discrepancy is yet argumentative. Similar studies have not been conducted in Iran.

\section{MATERIALS AND METHODS}

This is a descriptive-analytic study that is based on historical cohort method. This project was consented by the Ethics Committee of Shahid Sadoughi University of Medical Sciences. In this retrospective work, all cases of cancer patients were studied from 2004 to 2015 and the medical records of all women recognized with cervical SCC and AC treated at Shahid Sadoughi teaching hospital and Shahid Ramesanzadeh Radiotherapy Center were recovered. Demographic information and clinical-pathological characteristics of the patients were obtained based on the medical record available in the hospital as well as telephone calls. Patients whose information was incomplete were excluded from the study. Diagnosis was based on the slides stained with Hematoxylin \& Eosin. The overall survival was based on the time of diagnosis until death or the last visit. Statistical analysis included frequency table (for descriptive analysis) and Chi-Square test (for analytical analysis). Patient survival was assessed using Kaplan- Meier assessments, and multivariate analysis was done by the Cox regression mode.

A p value $<0.05$ was regard as statistically significant. Statistical analyses were done using SPSS. 17.

\section{RESULTS}

This study was done on 158 patients identified with cervical carcinoma. Their mean age at the time of diagnosis was $53.3987 \pm 1.02150$ years. According to histopathologic types 132 of the patients were classified as SCC with mean age of $52.4840 \pm 1.10612$ years; while 26 patients were identified as AC with mean age of $58.0385 \pm 2.49830$ years. Overall, the mean age of sexual debut was $17.5570 \pm 0.31892$ years and it was $17.8812 \pm 0.33242$ and $15.9615 \pm 0.90551$ years for SCC and AC respectively. Out of these patients, 138 patients $(78.3 \%)$ had one sexual partner and $20(12.7 \%)$ patients had two sexual partners in their life time. 47 patients $(29.7 \%)$ had a history of oral contraceptive consumption, among them 40 (30.3\%) patients with SCC had a history of oral contraceptive usage and $7(29.6 \%)$ patients with AD had used OCP.Two patients (1.3\%) had a history of smoking. 15 patients $(9.5 \%)$ had a history of hookah usage. 0 patients $(0 \%)$ had history of alcohol consumption. 17 of the patients with SCC (12.9\%) had Stage I disease, 50 (37.9\%) Stage II, 56 (42.4\%) Stage III, and 9 (6.8\%) Stage IV disease. 4 of the patients with AC (15.4\%) had Stage I disease, 17 (65.4\%) Stage II and 5 (19.2\%) Stage III. At the end of the project, 103 patients (78\%) with SCC were alive but 29 patients $(22 \%)$ had died; also 17 patients $(65.4 \%)$ with AC were alive but $9(36.4 \%)$ patients had died. The overall survival was $96.338 \pm 4.434$ months (95\% confidence interval) and it was $100.459 \pm 4.342$ and $54.475 \pm 5.334$ months for SCC and AC respectively. In this study, patients were divided into several groups according to their age (age group less than 50 years and more than 51 years) and age of sexual intercourse debut $(<18$ years vs group $\geq 19$ years). Patients with SCC pathology in age group less than 50 years survived longer than patients in age group more than 51 years and there was a significant relationship between age and overall survival $(p=0.01)$. Patients with $A C$ in age group less than 50 years survived shorter than patients in age group more than 51 years but this difference was not statistically significant $(\mathrm{p}=0.7)$ (table- 1$)$. SCC patients with history of oral contraceptive consumption had longer survival $(p=0.03)$ but this difference was not statistically significant in patients with AC pathology $(\mathrm{p}=0.7)$ (table-3). Cigarette smoking was associated with longer survival for both histologic types; however, hookah usage was associated inversely with survival in the two groups. Overall survival for patients with SCC decreased with earlier sexual debut and there was a significant relationship between age of first sexual intercourse and overall survival ( $p=0.01)$ but it was not true for $A C(p=0.82)$ (table-2). Overall survival was different between patients with early stages of SCC (stages I\&II) and advanced stages (stages III and IV) $(p=0.001)$. It was true about the patients with $A D(p=0.002)$ (table-4). Multivariate analysis using Cox proportional hazards model was conducted to evaluate the effect of histologic type of cervical carcinoma and stage on the survival. It showed that advanced stages and the type of carcinoma (AC) were predictors of death.

\section{Discussion}

Our findings showed that patients with cervical AC had a worse prognosis. A literature review reveals that there is no consensus on the prognosis of the two types of cervical cancers. Chen JL et al. found that the prognosis for adenocarcinoma was worse than for squamous cell carcinoma [4]. On the other hand, Shingleton $\mathrm{HM}$ et al. showed that histologic characteristics had no considerable result on survival [5]. On the contrary Jose H.T.G. Fregnani et al. [6] showed that the histological features of adenocarcinoma in terms of tumor grade, depth of invasion, lymphatic cannels permeation and regional lymph nodes metastases were better than those of squamous cell carcinoma. In contrast, the GOG study found no difference in the depth of invasion between these two tumors [7].

Grisaru et al [8] also revealed superior biologic conduct of $A C$ in relation to SCC. Jose' H.T.G. Fregnani et al. believed that AC was associated with poorer prognosis than those with SCC. However, no difference in the 5-year disease free survival rates were found between the AC and SCC groups [6]. To explain these discrepancies, we should note that 1-because AC of the cervix generally rises in the endocervical canal, diagnosis is frequently postponed. So, it is hard that lesions of analogous measure are being compared. So one reason that cervical adenocarcinoma has a worse prognosis may be due to a lack of early diagnosis.2- It should be noted that most scholars who believe that cervical adenocarcinoma has a worse prognosis than squamous cell carcinoma $[9,10]$ is due to the coverage of adenosquamous carcinoma with AC. Mention should be made that adeno squamous carcinoma has a worse prognosis than adenocarcinoma [7]. 3-Response to treatment is different. The shortage of concord in the remedy accomplished for AC of the uterine cervix is one of the agents that illustrates the hardness in comparing the studies. It is claimed that $A C$ may be more radioresistant than SCC [12]. Kasamatsu et al. showed that patients with early stages of cervical adenocarcinoma and squamous cell carcinoma who treated with radical surgery with or without post-surgical radiotherapy had the same prognosis [13].

There is some information that patients with cervical adenocarcinoma in early stages who underwent radical hysterectomy have better prognosis than patients who have only had radiotherapy. It is probably due to the lower radio sensitivity of $A C$ in adjustment with SCC [14]. Progression of more efficient therapy to ameliorate radiotherapy response and survival outcomes of AC/ASC histology is necessary [15]. In the present study 47 patients $(29.7 \%)$ had a history of oral contraceptive 
consumption, among them $40(30.3 \%)$ patients with SCC had a history of oral contraceptive usage and $7(29.6 \%)$ patients with AC had used OCP. Elementary studies tried the correlation between oral contraceptives and the risk of cervical neoplasia and they were reassuring. There is also a proposal of a powerful effect for AC than for SCC. Oral contraceptives may enforce multiplication of the human papillomaviruses, the eminent dubious factor for cervical cancer. Multiple [16,17] but not all [18] studies revealed increased risks of $A C$ and elevated risks of SCC [19] among oral contraceptives users, but complete control of confounders has been difficult. Although long-term use of birth control pills is known to be a predisposing factor for cervical cancer [20], it is not the only cause [21].

Oral contraceptives are associated with unprotected sexual contact that increment exposure to the HPV that creates cervical cancers. In the current study 2 patients (1.3\%) had a history of smoking. 15 patients $(9.5 \%)$ had a history of hookah use. 0 patients $(0 \%)$ had a history of alcohol consumption. A causal connection between cigarette smoking and invasive SCC has been proposed, maybe via a late-stage or propagational incident, albeit the mechanisms of act need better explanation [22]. Results of the current study showed that in the early and advanced stages, overall survival of patients with SCC was different $(p=0.001)$. It was true about the patients with $A C$ $(p=0.002)$. It is consistent with Nurliyana JUHA's findingsN [23] .In the present research, overall survival for SCC of cervical cancer decreased with earlier sexual debut and there was a significant relationship between age of first sexual intercourse and overall survival $(p=0.01)$ but AC histology did not have a significant relationship with overall survival $(p=0.82)$. Considering a transmissible etiology in the development of cervical cancer, a prominent effect of numerous sexual participants becomes clear. Early first intercourse is also associated with some residual consequences on risk.In conclusion; the results of the current study showed the prognosis is worse in patients with cervical AC than cervical SCC.

\section{CONCLUSION}

It seems that current screening practices are insufficient to detect a significant proportion of AC precursor lesions. Treatment for cervical adenocarcinoma appears to require revision. Different treatment strategies for $A C$ of the cervix may be needed. A larger scale study in multiple centers will be very helpful.

Table 1: The association between age and survival

\begin{tabular}{|c|c|c|c|c|c|}
\hline \multirow{2}{*}{ Type } & \multirow{2}{*}{ AGE(Year) } & \multirow{2}{*}{ Mean+SD (Month) } & \multicolumn{2}{|c|}{ Cl 95\% } & \multirow{2}{*}{ P-VALUE } \\
\hline & & & High & Low & \\
\hline \multirow{4}{*}{ SCC } & $<50$ & $112.3+\_5.2$ & 122.52 & 102.11 & \\
\hline & $\geq 50$ & $90.4+6.3$ & 102.75 & 77.97 & 0.01 \\
\hline & Total & $100.46 \_+4.34$ & 108.97 & 91.95 & \\
\hline & $<50$ & $53.37+10.22$ & 73.40 & 33.34 & \\
\hline \multirow[t]{2}{*}{$A C$} & $\geq 50$ & $56.15+6.64$ & 69.16 & 43.14 & 0.7 \\
\hline & Total & $54.47+5.33$ & 64.93 & 44.02 & \\
\hline
\end{tabular}

Table 2: The association between age of sexual debut and survival

\begin{tabular}{|c|c|c|c|c|c|}
\hline \multirow{2}{*}{ Type } & \multirow{2}{*}{ age of sexual debut } & \multirow{2}{*}{$\begin{array}{c}\text { Mean+SD } \\
\text { (Month) }\end{array}$} & \multicolumn{2}{|c|}{ Cl 95\% } & \multirow{2}{*}{ P-VALUE } \\
\hline & & & High & Low & \\
\hline \multirow{4}{*}{ SCC } & $<18$ & $92.94+\_5.65$ & 104 & 81.87 & \\
\hline & $\geq 18$ & 116.82+_5.09 & 126.81 & 106.84 & 0.01 \\
\hline & Total & $100.46+\_4.34$ & 108.97 & 91.95 & \\
\hline & $<18$ & $55.17+\_6.16$ & 67.25 & 43.1 & \\
\hline \multirow[t]{2}{*}{$A C$} & $\geq 18$ & $33.67+\_4.11$ & 41.73 & 25.6 & 0.82 \\
\hline & Total & $54.47+\_5.33$ & 64.93 & 44.02 & \\
\hline
\end{tabular}

Table 3: The association between OCP consumption and survival

\begin{tabular}{|c|c|c|c|c|c|}
\hline \multirow{2}{*}{ Type } & \multirow{2}{*}{ OCP consumption } & \multirow{2}{*}{$\begin{array}{c}\text { Mean+SD } \\
\text { (Month) }\end{array}$} & \multicolumn{2}{|c|}{ Cl 95\% } & \multirow{2}{*}{ P-VALUE } \\
\hline & & & High & Low & \\
\hline \multirow{3}{*}{ SCC } & + & $115.56+[5.42$ & 126.19 & 104.93 & \multirow{3}{*}{0.03} \\
\hline & - & $94.21+5.59$ & 105.16 & 83.25 & \\
\hline & Total & $100.46+\_4.34$ & 108.97 & 91.95 & \\
\hline \multirow{3}{*}{$A C$} & + & $59.14+10.29$ & 79.31 & 38.98 & \multirow{3}{*}{0.7} \\
\hline & - & $53.43+\_6.76$ & 66.69 & 40.18 & \\
\hline & Total & $54.47+\_5.33$ & 64.93 & 44.02 & \\
\hline
\end{tabular}


Table 4: The association between stage and survival

\begin{tabular}{|c|c|c|c|c|c|}
\hline \multirow{2}{*}{ Type } & \multirow{2}{*}{ Stage } & \multirow{2}{*}{$\begin{array}{c}\text { Mean+SD } \\
\text { (Month) }\end{array}$} & \multicolumn{2}{|c|}{ Cl 95\% } & \multirow{2}{*}{ P-VALUE } \\
\hline & & & High & Low & \\
\hline \multirow{5}{*}{ SCC } & I & $122.67+\_1.90$ & 126.40 & 118.93 & \multirow{5}{*}{0.001} \\
\hline & II & $112.36+55.6$ & 123.32 & 101.40 & \\
\hline & III & $90.14+7.43$ & 104.70 & 75.58 & \\
\hline & IV & 33.56+_9.07 & 51.34 & 15.77 & \\
\hline & Total & $100.46+\_4.34$ & 108.97 & 91.95 & \\
\hline \multirow{4}{*}{$A C$} & I & 72 & 72 & 72 & \multirow{4}{*}{0.002} \\
\hline & II & $57.80+5.57$ & 68.71 & 46.88 & \\
\hline & III & $19.4+66.40$ & 31.94 & 6.86 & \\
\hline & Total & $54.47+\_5.33$ & 64.93 & 44.02 & \\
\hline
\end{tabular}

\section{Acknowledgements}

None.

Contributions: All the authors contributed in the preparation of this research and article.

\section{Conflict of Interest: None.}

\section{REFERENCES}

1. Chen W, Zheng R, Baade PD, Zhang S, Zeng H, Bray F, et al, Cancer statistics in China, 2015. CA Cancer J Clin 2016;66(2):115-132

2. Siegel RL, Miller KD, Jemal A. Cancer statistics, 2016. CA Cancer J Clin 2016;66(1):7-30

3. Vinh-Hung V, Bourgain C, Vlastos G, Cserni G, De Ridder $\mathrm{M}$, Storme $\mathrm{G}$, et al. Prognostic value of histopathology and trends in cervical cancer: a SEER population study.BMC Cancer 2007;7:164

4. Chen JL, Huang CY, Huang YS, Chen RJ, Wang CW, Chen $\mathrm{YH}$, et al, Differential clinical characteristics, treatment response and prognosis of locally advanced adenocarcinoma/adenosquamous carcinoma and squamous cell carcinoma of cervix treated with definitive radiotherapy. Oral contraceptives, Acta Obstet Gynecol Scand 2014;93(7):661-668

5. Shingleton HM, Bell MC, Fremgen A, Chmiel JS, Russell $\mathrm{AH}$, Jones WB, et al, Is there really a difference in survival of women with squamous cell carcinoma, denocarcinoma, and adenosquamous cell carcinoma of the cervix? Cancer. 1995; 76(10):1948-55.

6. Jose HTG, Fregnani, Fernando A, Soares, Pablo R Novik, Ademar Lopes et al, Comparison of biological behavior between early-stage adenocarcinoma and squamous cell carcinoma of the uterine cervix, European Journal of Obstetrics \& Gynecology and Reproductive Biology 2008; 136:215-223

7. Look KY, Brunetto VL, Clarke-Pearson DL et al. An analysis of cell type in patients with surgically staged stage IB carcinoma of the cervix: a Gynecologic Oncology Group study. Gynecol Oncol, 1996;63:304-11

8. Grisaru D, Covens A, Chapman B, et al. Does histology influence prognosis in patients with early-stage cervical carcinoma? Cancer, 2001;92:2999-3004

9. Takeda N, Sakuragi N, Takeda M, Okamoto K, Kuwabara $\mathrm{M}$, Negishi $\mathrm{H}$, et al. Multivariable analysis of histopathologic prognostic factors for invasive cervical cancer treated with radical hysterectomy and systematic retroperitoneal lymphadenectomy. Acta Obstet Gynecol Scand, 2002;81:1144-51

10. Davy ML, Dodd TJ, Luke CG, Roder DM. Cervical cancer: effect of glandular cell type on prognosis, treatment, and survival. Obstet Gynecol, 2003;101:38-45

11. West CM, Davidson SE, Burt PA, Hunter RD. The intrinsic radiosensitivity of cervical carcinoma: correlations with clinical data. Int J Radiat Oncol Biol Phys, 1995;31:841-6.

12. Kasamatsu T, Onda T, Sawada M, Kato T, Ikeda S, Sasajima Y, et al. Radical hysterectomy for FIGO stage IIIB adenocarcinoma of the uterine cervix. Br J Cancer 2009; 100:1400-5

13. Eifel PJ, Burke TW, Morris M, Smith TL. Adenocarcinoma as an independent risk factor for disease recurrence in patients with stage IB cervical carcinoma. Gynecol Oncol 1995;59:38-44

14. Juan Zhou, San-Gang Wu, Jia-Yuan Sun, Feng-Yan Li, Huan-Xin Lin, Qiong-Hua Chen et al, Comparison of clinical outcomes of squamous cell carcinoma, adenocarcinoma, and adenosquamous carcinoma of the uterine cervix after definitive radiotherapy: a population-based analysis, J Cancer Res Clin Oncol DOI 10.1007/s00432-016-2246-9

15. Thomas DB, Ray RM. The WHO Collaborative Study of Neoplasia and Steroid Contraceptives. Oral contraceptives and invasive adenocarcinomas and adenosquamous carcinomas of the uterine cervix. Am. J. Epidemiol, 1996;144:281-289,

16. Ursin G, Peters RK, Henderson BE, d'Ablaing G, Monroe $\mathrm{KR}$, Pike MC. Oral contraceptive use and adenocarcinoma of the cervix. Lancet, ,1994; 344:1390-1394

17. Honore LH, Koch M, Brown LB. Comparison of oral contraceptive use in women with adenocarcinoma and squamous cell carcinoma of the uterine cervix.Gynecol. Obstet. Investig. 1991; 32:98-101

18. Irwin KL, Rosero-Bixby L, Oberle MW, Lee NC, Whatley AS, Fortney JA et al. Oral contraceptives and cervical cancer risk in Costa Rica: detection bias or causal association?. J. Am. Med. Assoc, 1988; 259:59-64

19. Moreno V, Bosch FX, Munoz N, et al., International Agency for Research on Cancer. Multicentric Cervical Cancer Study Group.Effect of oral contraceptives on risk of cervical cancer in women with human papillomavirus infection: the IARC multicentric case-control study. Lancet 2002;359:1085-92

20. Berrington de Gonzalez A, Sweetland S, Green J. Comparison of risk factors for squamous cell and adenocarcinomas of the cervix: a metaanalysis. Br J Cancer 
2004;90:1787-91

21. Louise A Brinton, Catherine Schairer, William Haenszel, et al, Cigarette Smoking and Invasive Cervical Cancer JAMA. 1986;255(23):3265-3269.

22. Nurliyana JUHAN, Nuradhiathy ABD RAZAK, Yong Zulina ZUBAIRI. Muhammad Naeem KHATTAK, and Nyi Nyi NAING, Survey of Patients with Cervical Cancer in Hospital UniversitiSains Malaysia: Survival Data Analysis with TimeDependent Covariate, Iran J Public Health. 2013 Sep; 42(9):980-987 